\title{
Extension of the Single-Event Methodology to Metal Catalysis: Application to Fischer-Tropsch Synthesis
}

\author{
G. Lozano-Blanco', K. Surla ${ }^{2}$, J.W. Thybaut ${ }^{1}$ and G.B. Marin ${ }^{1}$ \\ 1 Laboratory of Chemical Technology, Ghent University, Kriigslaan 281-S5, 9000 Ghent-Belgium \\ 2 Institut français du pétrole, IFP Energies nouvelles, BP 3, 69390 Vernaison - France \\ e-mail: gisela.lozano@ugent.be - joris.thybaut@ugent.be -guy.marin@ugent.be - karine.surla@ifpenergiesnouvelles.fr \\ * Corresponding author
}

Résumé - Extension de la méthodologie des événements constitutifs à la catalyse métallique : Application à la synthèse Fischer-Tropsch - La méthodologie par événements constitutifs a été étendue à la catalyse métallique en utilisant la synthèse Fischer-Tropsch sur un catalyseur au fer comme cas d'étude. Le mécanisme réactionnel a été décomposé en étapes élémentaires qui peuvent être classées par type de réactions, telles que l'élimination réductrice, l'élimination d'hydrure en $\beta$, et l'insertion de groupe méthylène. Un code de calcul a été développé pour générer le réseau réactionnel impliquant ces étapes élémentaires. La représentation des réactifs et des espèces intermédiaires prend en compte explicitement les liaisons carbone-métal et inclut la présence d'atomes d'oxygène. Le modèle a été validé sur une base de données obtenues sur un catalyseur à base de fer à $623 \mathrm{~K}$, sur une plage de 0,6 à $2,1 \mathrm{MPa}$, un ratio $\mathrm{H}_{2} / \mathrm{CO}$ en entrée variant de 2 à 6 . Quatorze paramètres, dont 10 énergies d'activation et 4 enthalpies de chimisorption atomique ont été ajustés aux données expérimentales. Les tendances observées expérimentalement pour les rendements en alcanes et alcènes-1 en fonction du nombre de carbones sont correctement reproduites, ainsi que les rendements molaires des produits non-hydrocarbures.

\begin{abstract}
Extension of the Single-Event Methodology to Metal Catalysis: Application to FischerTropsch Synthesis - The single-event methodology has been extended to metal catalysis using Fischer-Tropsch synthesis on an iron-based catalyst as case study. The reaction mechanism has been assessed in terms of elementary steps that could be categorized in reaction families such as reductive elimination, $\beta$-hydride elimination and methylene insertion. A computer code has been developed for the generation of the reaction network containing these elementary steps. The representation of reacting and intermediate species explicitly takes into account metal-carbon bonds as well as the presence of oxygen. The model has been validated using iron-based catalytic data at $623 \mathrm{~K}, 0.6$ to $2.1 \mathrm{MPa}$, inlet molar $\mathrm{H}_{2} / \mathrm{CO}$ ratio between 2 and 6.14 parameters, among which 10 activation energies and 4 atomic chemisorption enthalpies have been adjusted to the experimental data. Experimentally observed trends in alkane and 1-alkene product yields with the carbon number were adequately reproduced as well as the individual molar yields of the non-hydrocarbon products.
\end{abstract}




\section{LIST OF SYMBOLS}

\section{Roman symbols}

$\begin{array}{ll}* & \text { Vacant site } \\ \neq & \text { Transition state } \\ A & \text { Pre-exponential factor }\left(\mathrm{MPa}^{-1} \mathrm{~s}^{-1} \mathrm{or} \mathrm{s}^{-1}\right) \\ C & \text { Concentration }\left(\mathrm{mol} / \mathrm{kg}_{\mathrm{cat}}\right) \\ c n & \text { Carbon number } \\ E_{a} & \text { Activation energy }(\mathrm{J} / \mathrm{mol}) \\ F & \text { Molar flow rate }(\mathrm{mol} / \mathrm{s}) \\ H & \text { Enthalpy }(\mathrm{J} / \mathrm{mol}) \\ k & \text { Kinetic coefficient of an elementary step }\left(\mathrm{MPa}^{-1} \mathrm{~s}^{-1}\right.\end{array}$

$\underline{M}$ Metal atom belonging to the lattice of the iron oxide phase

$n \quad$ Number

nob Number of observations

nresp Number of responses

$\underline{O}$ Oxygen atom belonging to the lattice of the iron oxide phase

$p \quad$ Pressure (MPa)

$Q \quad$ Chemisorption enthalpy $(\mathrm{kJ} / \mathrm{mol})$

$R \quad$ Net production rate $\left(\mathrm{mol} / \mathrm{kg}_{\text {cat }} \mathrm{s}\right)$

$S \quad$ Entropy $(\mathrm{J} / \mathrm{mol} / \mathrm{K})$

SEMK Single-Event MicroKinetics

$S S Q \quad$ Sum of squares of residuals between observed and calculated response values $\left((\mathrm{mol} / \mathrm{mol})^{2}\right)$

$T \quad$ Absolute temperature (K)

W Catalyst mass $(\mathrm{kg})$

$w \quad$ Weight fraction (-)

y Molar yield or conversion ( $\mathrm{mol} / \mathrm{mol})$

$z \quad$ Number of nearest neighbor atoms

\section{Constants}

$h \quad$ Planck constant $\left(6.626068 \times 10^{-34} \mathrm{~m}^{2} \mathrm{~kg} \mathrm{~s}^{-1}\right)$

$k_{B} \quad$ Boltzmann constant $\left(1.3806503 \times 10^{-23} \mathrm{~m}^{2} \mathrm{~kg} \mathrm{~s}^{-2} \mathrm{~K}^{-1}\right)$

$R \quad$ Universal gas constant $\left(8.3144 \mathrm{~J} \mathrm{~mol}^{-1} \mathrm{~K}^{-1}\right)$

\section{Greek symbols}

$\alpha \quad$ Chain growth probability (-)

$\beta \quad$ Vector of parameters

$\sigma \quad$ Symmetry number

$\sigma^{i j} \quad$ Inverse of the covariance between the experimental errors associated with measurements of the $i$-th and $j$-th response

$\Delta \quad$ Difference

$v \quad$ Stoichiometric coefficient

\section{Subscripts}

chem Chemisorption

des Desorption

gl Global

oa Oxidative addition

prop Propagation

$R \quad$ Reaction

$r \quad$ Reactant

re Reductive elimination

surf Surface

term Termination

tot Total

\section{Superscripts}

$\begin{array}{ll}\sim & \text { Single-event } \\ \wedge & \text { Model calculated value } \\ 0 & \text { Standard state }(0.1 \mathrm{MPa}) \text { or initial } \\ \text { for } & \text { Forward } \\ \text { rev } & \text { Reverse }\end{array}$

\section{INTRODUCTION}

The use of detailed kinetic models enables to achieve accurate product yields predictions over a wide range of operation conditions and varying feedstock compositions. One way to develop such a detailed kinetic model is to apply the singleevent methodology, widely described in literature [1]. It leads to fundamental kinetic models based on a precise mechanistic description of the elementary steps occurring on the catalyst surface. The corresponding, detailed reaction network generally requires the use of a computer algorithm for its generation. Within this reaction network, the single-event concept is applied to reduce the number of adjustable kinetic parameters, by recognizing that the differences in rate coefficients belonging to a given reaction family are only due to symmetry effects.

Single-Event MicroKinetic (SEMK) models have mainly been applied to acid catalysis in processes such as reforming [2], hydrocracking [3] or catalytic cracking [4]. Although an analogous methodology for metal catalyzed reactions has been proposed by Van Engelandt [5] and Verstraete [2] for (de)-hydrogenation and hydrogenolysis, it has never been fully developed. The scope of the present work is to extend the single-event kinetic methodology to metal catalyzed reactions, with Fischer-Tropsch synthesis as example reaction. This process occurs on a monometallic catalyst on which typical reactions such as the formation and scission of C-C and $\mathrm{C}-\mathrm{H}$ bonds occur for homologous series of hydrocarbons. The latter allows the reduction of the number of adjustable parameters. In addition, a wide product spectrum is obtained, 
which makes it appropriate for reaction network generation using a computer algorithm.

Microkinetic models for Fischer-Tropsch synthesis on cobalt and nickel catalysts have already been proposed in literature $[6,7]$. Klinke and Broadbelt [6] described the production of alkanes and alkenes up to three carbon atoms in a transient reactor at $493 \mathrm{~K}$ and $523 \mathrm{~K}$ over $\mathrm{Co}(0001)$ surfaces applying linear free energy relationships. Storsaeter et al. [7] calculated the activation energies of a reaction network up to two carbon atoms for several surface mechanisms by a phenomenological method [8], however, a comparison with experimental data was not shown since a further parameter adjustment was required.

Fischer-Tropsch synthesis involves a large number of species that must be generated by means of a computer algorithm [9]. Network generation programs for Fischer-Tropsch synthesis have been proposed previously $[6,10]$. Temkin et al. [10] applies topology identifiers as a means to set plausible elementary steps. Klinke and Broadbelt [6] use bondelectron matrices to represent the molecules and reactions are generated by performing the corresponding operations on these matrices.

Fischer-Tropsch synthesis is the conversion of synthesis gas containing carbon monoxide and hydrogen into clean transportation fuels and chemicals. The overall reaction can be written as:

$$
n \mathrm{CO}+2 n \mathrm{H}_{2} \rightarrow-\left(\mathrm{CH}_{2}\right)_{n}-+n \mathrm{H}_{2} \mathrm{O}
$$

Synthesis gas can be obtained from any carbonaceous material, preferentially containing hydrogen such as coal and natural gas. Fischer-Tropsch products compete with crude oil derived fuels in worldwide markets. Advantages of the Fischer-Tropsch hydrocarbons are for example the absence of sulfur, nitrogen and the low aromatic content. The increasing prices and depleting reserves of crude oil, together with the necessity of monetizing "stranded" natural gas have renewed the interest in Fischer-Tropsch synthesis in the last decades $[11,12]$.

Fischer-Tropsch synthesis produces a wide range of alkenes, alkanes and oxygenates. The product slate depends on operating conditions such as temperature, $\mathrm{CO} / \mathrm{H}_{2}$ feedstock ratio, total pressure, catalyst type and promoters [13]. The hydrocarbons are predominantly linear and the double bond in the alkenes is mostly terminal. Minor amounts of oxygenated components, i.e., alcohols, aldehydes, ketones and acids, are usually produced. Water is also one of the main primary products, together with carbon dioxide produced by the water-gas shift if operating with iron catalysts, according to:

$$
\mathrm{H}_{2} \mathrm{O}+\mathrm{CO} \leftrightarrow \mathrm{CO}_{2}+\mathrm{H}_{2}
$$

In general, linear $n$-alkanes and 1 -alkenes are regarded as primary products. The latter are obtained at low temperatures, when the temperature increases, secondary reactions lead to skeletal and double bonds isomers [14]. Alkenes, mainly 1-alkenes, make up more than $50 \%$ of the product yields. Alcohols are generally considered as side-products of the reaction. However, on specific catalysts under particular conditions, e.g., at higher temperatures, alcohols can be produced in significant amounts. Oxygenated products, i.e., alcohols, aldehydes, ketones and acids, interconvert under Fischer-Tropsch synthesis conditions [13], e.g. ketones are formed from alcohols at high temperatures and interconversion between alcohols and aldehydes has been observed over a $\mathrm{Co} / \mathrm{MnO}$ catalyst [15]. Naphthenes and aromatic compounds are produced in small amounts in fixed and fluidized reactors on iron-based catalyst only.

For over 75 years, the elementary steps occurring on the metal surface have been a matter of controversy. However, the fact that the chain growth occurs through the stepwise addition of single carbon monomers is not a matter of discussion. This is because the product distributions may be described by equations first developed for polymerization reactions [16]:

$$
w_{n}=n(1-\alpha)^{2} \alpha^{n-1}
$$

$w_{n}$ being the fraction of the products with $n$ carbon atoms obtained with a chain growth probability $\alpha$ independent of carbon number. The analogy was first noticed by Anderson [16]. The chain growth probability can be expressed as the ratio between the rate of propagation and the sum of rates of propagation and termination [17]:

$$
\alpha=\frac{R_{\text {prop }}}{R_{\text {prop }}+R_{\text {term }}}
$$

However, the so-called Anderson-Schulz-Flory (ASF) product distribution does not fully agree with experimental observations. In particular, the carbon number distribution on a molar basis is high for $\mathrm{C}_{1}$, has a minimum at $\mathrm{C}_{2}$, has a maximum again at $\mathrm{C}_{3}$ or $\mathrm{C}_{4}$, and then decreases monotonically as the carbon number increases [16]. Such deviations have been observed for iron, cobalt and ruthenium catalysts and have been interpreted as the superposition of two or more ASF distributions, attributed to different factors, e.g., the existence of structurally different sites leading to different growth probabilities [18] or the existence of more than one chain growth mechanism [19]. In general, the most accepted explanation is the re-adsorption and re-incorporation of 1-alkenes in the chain growth [17, 19-21].

Commercially Fischer-Tropsch synthesis is carried out over iron and cobalt catalysts. The use of one catalyst or another depends on the desired product selectivities, the operating, temperature, reactor type and feedstock origin which determines the $\mathrm{H}_{2} / \mathrm{CO}$ inlet ratio [12]. Currently, iron catalysts are used at high and low temperatures and cobalt catalysts only at the lower temperature regime. Cobalt is known as a more hydrogenating catalyst than iron and, hence, is used to obtain linear waxes or diesel-range products while iron-based catalysts rather lead to gasoline-range products 
and alkenes. Additionally, the water-gas shift reaction is only occurring over iron catalysts, which influences the carbon monoxide conversion and the $\mathrm{H}_{2} / \mathrm{CO}$ usage ratio.

The scope of this work is to extend the single-event methodology to metal catalysis using Fischer-Tropsch synthesis as example. The resulting model goes beyond those already described in the literature in the sense that it considers a more extended reaction network and that it is applied to an iron-based catalyst.

\section{PROCEDURES}

\subsection{Experiments}

In this work, the validation of the microkinetic model is performed by model regression to experimental data obtained over an iron-based catalyst. The data set used was obtained in a previous work [22]. Experiments were performed in a tubular fixed-bed reactor using a commercial, precipitated iron catalyst at steady-state under isothermal and non deactivating conditions. The range of experimental conditions investigated is presented in Table 1. Carbon monoxide conversions ranged from 12 to $100 \%$. Within this paper, the model regression is limited to the data at $623 \mathrm{~K}$ only, because the most experimental data are available at this temperature.

TABLE 1

Experimental conditions studied for Fischer-Tropsch synthesis on iron based catalyst

\begin{tabular}{c|c|c|c|c}
\hline$T(\mathrm{~K})$ & $p_{\text {tot }}(\mathrm{MPa})$ & $\begin{array}{c}F_{\mathrm{H}_{2}}^{0} / F_{\mathrm{CO}}^{0} \\
(\mathrm{~mol} / \mathrm{mol})\end{array}$ & $\begin{array}{c}W / F_{\mathrm{CO}}^{0} \\
(\mathrm{~kg} \mathrm{~s} / \mathrm{mol})\end{array}$ & $\begin{array}{c}\text { Number } \\
\text { of conditions }\end{array}$ \\
\hline 623 & $0.6,1.1,1.6,2.1$ & $2,3,4,6$ & $9.2-63.0$ & 33 \\
\hline 573 & $0.6,1.1,2.1$ & $2,3,6$ & $7.9-82.0$ & 25 \\
\hline 553 & $0.6,1.1,2.1$ & 3,6 & $12.0-63.0$ & 19 \\
\hline 523 & $1.1,2.1$ & 3,6 & $17.0-63.0$ & 13 \\
\hline
\end{tabular}

The description of the experimental set-up and the characterization of the catalyst have been published previously [23-25]. However, some basic information is summarized here. The tubular reactor, $0.27 \mathrm{~m}$ in length and $0.021 \mathrm{~m}$ inside diameter, was loaded with $5 \mathrm{~g}$ of catalyst. The mean diameter of the catalyst pellets was $0.4 \mathrm{~mm}$. For the dilution of the catalyst bed $50 \mathrm{~g}$ of steatite of aluminum oxide of the same diameter size was used.

The amount of iron atoms exposed in the catalyst is 3\% [25], which corresponds to $240 \mathrm{mmol}$ of surface iron atoms per kilogram of catalyst. Approximately $75 \%$ of the surface of the catalyst is a carbide phase and $25 \%$ an oxidized phase. Hence, a constant value of $180 \mathrm{mmol}$ iron/ $\mathrm{kg}$ catalyst has been considered as total concentration of iron atoms on the surface for hydrocarbon-forming reactions and $60 \mathrm{mmol}$ iron/kg catalyst for the water-gas shift reaction. Since oxygen and iron atoms are placed alternately on the surface sustaining a neutral charge, a concentration of $60 \mathrm{mmol}$ oxygen $/ \mathrm{kg}$ catalyst is applied. The $z$ number of neighbors of a particular atom has been assumed constant and equal to four.

The intrinsic character of the observed kinetics was verified by the criteria of Weisz and Prater and Mears [26] at $623 \mathrm{~K}$ and $2.1 \mathrm{MPa}$, assuming that the pores were filled with hydrocarbon wax. Experimentally, the hydrocarbon wax was analyzed and revealed 1 -alkenes and $n$-alkanes up to carbon number 100 [12, 24, 25].

The most abundant carbon-containing products were methane, $n$-alkanes, 1 -alkenes and carbon dioxide. Initial rate studies evidenced that carbon dioxide was probably formed on different sites than the hydrocarbons, in agreement with other experimental observations reported in literature [27].

Hydrocarbons up to carbon number 15 were experimentally observed although quantitative measurements were limited to hydrocarbons up to carbon number 10 . As a consequence a reaction network up to 10 carbon atoms is used.

Branched hydrocarbons and alcohols were also observed but their concentrations were significantly smaller than those of linear alkanes and 1-alkenes. As a consequence, iso-alkanes and alcohols were included in the $n$-alkanes response of the corresponding carbon number and the iso-alkenes were added to the 1-alkenes with the same carbon number.

\subsection{Model Regression}

Since the experimental data were obtained in a fixed bed reactor operating in an integral way, a pseudo-homogeneous one-dimensional model was applied to calculate molar yields and conversions $[26,28]$. Hence, for an experiment $i$, the continuity equation of a reference product component $j$ is:

$$
\frac{d y_{i j}}{d\left(W_{i} / F_{i j}^{0}\right)}=R_{i j}
$$

with initial conditions:

$$
y_{i j}(0)=0 \text {, when } W_{i} / F_{i j}^{0}=0
$$

The calculation of the net production rates of component $j$ are discussed in Section 3.3. The pseudo-steady state approximation is applied to all surface species, cfr. infra, resulting in a set of non-linear algebraic equations.

The estimation of the kinetic parameters is performed by minimizing the objective function $\operatorname{SSQ}(\beta)$ with respect to the model parameter vector $\beta\left(b_{l}, l=1, \ldots\right.$, npar $)$ [29]:

$\operatorname{SSQ}(\beta)=\sum_{j=1}^{\text {nresp }} \sum_{k=1}^{\text {nresp }} \sigma^{j k} \sum_{i=1}^{n o b}\left(y_{i j}-\hat{y}_{i j}\right)\left(y_{i k}-\hat{y}_{i k}\right) \stackrel{\beta}{\longrightarrow} \operatorname{minimum}(7)$

where $y_{i j}$ and $y_{i k}$ are the $j$-th and $k$-th experimental responses in the $i$-th observation, $\hat{y}_{i j}$ and $\hat{y}_{i k}$ are the $j$-th and $k$-th 
response values calculated for the observation $i$, and $\sigma^{j k}$ is the element for the $j$-th and the $k$-th responses of $\sum^{-1}$, the inverse of the error covariance matrix [29].

The objective function is minimized using a combination of multi-response Rosenbrock and Levenberg-Marquardt algorithms [30, 31]. The in-house developed Rosenbrock code is used to find an adequate direction leading to a possible optimum, which is reached by using the ODRPACK package [32], available in Netlib library [33] performing the regression by the method of ordinary least squares.

Initially, the inverse error covariance matrix is reduced to a diagonal error matrix calculated from the reciprocal of the squared value of the responses. The obtained parameter estimates in this regression are used to estimate the elements of the error covariance matrix. Based on the latter, a second regression is performed leading to the final set of parameter estimates.

The model regression is performed by applying the objective function given in Equation (7). The total number of observations is 33 . Depending on the operating conditions, $n$-alkanes and 1-alkenes up to carbon number 8,9 or 10 were reported. A reaction network up to 10 carbon atoms is used and, hence, for the molecules not observed in a particular experiment, the corresponding weighting factors are set to zero. The molar yields and conversions of carbon monoxide, hydrogen, carbon dioxide, water and the hydrocarbons enumerated above are the responses contained in the objective function (Eq. 7) and are calculated via integration of the reactor model equations (Eq.5).

The total number of equations to solve is 52 , from which 23 are ordinary differential equations and 29 are algebraic equations. Three of the observations were eliminated on the basis of mass balance verifications. Hence, the total number of observations used in the present regression is 30 .

\section{DEVELOPMENT OF A FUNDAMENTAL REACTION NETWORK FOR FISCHER-TROPSCH SYNTHESIS}

As discussed in the introduction, the knowledge of the chemical transformations on the catalyst surface via elementary steps is required for the formulation of a microkinetic model. After analyzing the typical product distributions and the most relevant mechanistic proposals, a reliable reaction mechanism was selected for the hydrocarbon forming reactions and the water-gas shift on iron-based catalysis, as will be shown in the next sections.

\subsection{Reaction Mechanism}

A reliable reaction network involving well-known reactions in organometallic chemistry and heterogeneous catalysis has been selected from the mechanistic proposals given in literature for Fischer-Tropsch synthesis and water-gas shift under Fischer-Tropsch synthesis conditions.

\subsubsection{Hydrocarbon Forming Reactions}

The reaction mechanism selected for the hydrocarbon forming reactions is given in terms of elementary steps in Table 2 . Since Fischer-Tropsch synthesis follows a polymerization type of kinetics, the elementary steps can be explained in terms of chain initiation, chain growth and chain termination.

The chain initiation consists of the chemisorption and dissociation of hydrogen and carbon monoxide, i.e., steps (1), (2) and (3). The formation of the building-blocks, i.e., methylene and methyl species, occurs through consecutive hydrogenations of the surface species, i.e., steps (4), (5) and (6).

The so-called "carbene" mechanism was selected for describing the chain growth of the hydrocarbon moieties over iron catalysts. The "carbene" mechanism is the most popular mechanism for Fischer-Tropsch synthesis and consists of the insertion of methylene species into growing metal-alkyl species and is present as step (7) in Table $2[34,35]$. This reaction is well accepted in heterogeneous catalysis [36, 37].

For the chain termination, the formation of alkanes occurs through reductive elimination of metal alkyl species, step (8), while the formation of alkenes occurs through $\beta$-hydride elimination followed by desorption of metal alkenes, steps (9) and (10) [35, 38]. The formation of water occurs also through partial hydrogenation steps of the oxygenated surface species, i.e., steps (11) and (12).

TABLE 2

Detailed reaction mechanism for Fischer-Tropsch synthesis

\begin{tabular}{|c|c|}
\hline \multicolumn{2}{|l|}{ Reaction family/elementary reaction } \\
\hline Chain initiation & \\
\hline $\mathrm{H}_{2}+2 \mathrm{M} \leftrightarrow 2 \mathrm{MH}$ & (1) \\
\hline $\mathrm{CO}+2 \mathrm{M} \leftrightarrow \mathrm{MMCO}$ & (2) \\
\hline $\mathrm{MMCO}+3 \mathrm{M} \leftrightarrow \mathrm{MMMC}+\mathrm{MMO}$ & (3) \\
\hline $\mathrm{MMMC}+\mathrm{MH} \leftrightarrow \mathrm{MMMCH}+\mathrm{M}$ & (4) \\
\hline $\mathrm{MMMCH}+\mathrm{MH} \leftrightarrow \mathrm{MMCH}_{2}+2 \mathrm{M}$ & (5) \\
\hline $\mathrm{MMCH}_{2}+\mathrm{MH} \leftrightarrow \mathrm{MCH}_{3}+2 \mathrm{M}$ & $(6)$ \\
\hline Chain growth ("carbene" mechanism) & \\
\hline $\mathrm{MC}_{n} \mathrm{H}_{2 n+1}+\mathrm{MMCH}_{2} \leftrightarrow \mathrm{MC}_{n+1} \mathrm{H}_{2 n+3}+2 \mathrm{M}$ & $(7)$ \\
\hline Chain termination & \\
\hline $\mathrm{MC}_{n} \mathrm{H}_{2 n+1}+\mathrm{MH} \leftrightarrow \mathrm{C}_{n} \mathrm{H}_{2 n+2}+2 \mathrm{M}$ & $(8)$ \\
\hline $\mathrm{MC}_{n} \mathrm{H}_{2 n+1}+\mathrm{M} \leftrightarrow \mathrm{MC}_{n} \mathrm{H}_{2 n}+\mathrm{MH}$ & (9) \\
\hline $\mathrm{MC}_{n} \mathrm{H}_{2 n} \leftrightarrow \mathrm{C}_{n} \mathrm{H}_{2 n}+\mathrm{M}$ & (10) \\
\hline Water formation & \\
\hline $\mathrm{MMO}+\mathrm{MH} \leftrightarrow \mathrm{MOH}+2 \mathrm{M}$ & (11) \\
\hline $\mathrm{MOH}+\mathrm{MH} \leftrightarrow \mathrm{H}_{2} \mathrm{O}+2 \mathrm{M}$ & (12) \\
\hline
\end{tabular}

\subsubsection{Water-Gas Shift}

The water-gas shift reaction is an exothermic and reversible reaction where carbon monoxide and water produce carbon dioxide and hydrogen [39]:

$$
\mathrm{H}_{2} \mathrm{O}+\mathrm{CO} \leftrightarrow \mathrm{CO}_{2}+\mathrm{H}_{2}
$$


Water-gas shift and formation of hydrocarbons on iron catalysts proceed on different active sites [27, 40, 41]. While the hydrocarbon-forming reactions occur on iron carbides, the water-gas shift reaction occurs on iron oxide, more specifically on magnetite $\left(\mathrm{Fe}_{3} \mathrm{O}_{4}\right)$. Two reaction mechanisms are generally accepted for the water-gas shift on metal oxides, i.e., the so-called regenerative mechanism and the formate mechanism [39].

The regenerative mechanism occurs through the alternate oxidation and reduction of the surface:

$$
\begin{aligned}
& \mathrm{H}_{2} \mathrm{O}+* \leftrightarrow \mathrm{H}_{2}+\mathrm{O}^{*} \\
& \mathrm{CO}+\mathrm{O}^{*} \leftrightarrow \mathrm{CO}_{2}+*
\end{aligned}
$$

where * represents a vacant site on the surface produced by the removal of an oxygen atom, and $\mathrm{O}^{*}$ is an oxygen-containing surface site.

The formate mechanism involves the formation of a formate species as intermediate. In Figure 1, the elementary steps involved in the formate mechanism according to Rethwisch and Dumesic [42] are displayed. In this figure, step a) shows the dissociation of water. Water is a dipole molecule with good donor properties. Hence, the dissociation of water into $\mathrm{H}^{+}$and $\mathrm{OH}^{-}$readily occurs on metal oxide surfaces, especially in the presence of defects. As shown in Figure 1, hydroxyl adsorbs on Lewis-acidic cations of the surface. Step b) displays the chemisorption of carbon monoxide. The reaction of carbon monoxide with a surface hydroxyl group to yield formate species in step c) and carbon dioxide desorption from a carbonate species in step e) are well-known reactions on metal oxides [43]. The dissociation of hydrogen on the iron oxide in step f) suggests magnetite is a relatively high reactive metal oxide. If iron cations do not undergo changes in oxidation state, the regenerative mechanism cannot occur. The presence of other metal oxides in the catalyst, e.g., $\mathrm{Al}_{2} \mathrm{O}_{3}, \mathrm{TiO}_{2}$ or $\mathrm{SiO}_{2}$ supports, stabilize the ferrous ions by forming mixed oxides [42]. In this study, silicon was added as promoter [25]. Hence, the formate mechanism is the most presumable mechanism for supported magnetite [27, 42, 44].

As displayed in Figure 1, the reaction mechanism consists of six elementary reactions where two different types of sites are identified, i.e., the metal atom and the oxygen anion:

$$
\begin{gathered}
\mathrm{H}_{2} \mathrm{O}+\underline{M}+\underline{O} \stackrel{1}{\longleftrightarrow} \underline{M}-\mathrm{OH}+\underline{O}-\mathrm{H} \\
\mathrm{CO}+\underline{M} \stackrel{2}{\longleftrightarrow} \underline{M}-\mathrm{CO} \\
\underline{M}-\mathrm{CO}+\underline{O}-\mathrm{H} \stackrel{3}{\longleftrightarrow} \underline{O}-\mathrm{CHO}-\underline{M} \\
\underline{O}-\mathrm{CHO}-\underline{M}+\underline{M}-\mathrm{OH}+\underline{O} \stackrel{4}{\longleftrightarrow} \underline{O}-\mathrm{COOH}-\underline{M}+\underline{O}-\mathrm{H}+\underline{M} \\
\underline{O}-\mathrm{COOH}-\underline{M} \stackrel{5}{\longleftrightarrow} \mathrm{CO}_{2}+\underline{O}-\mathrm{H}+\underline{M} \\
2 \underline{O}-\mathrm{H} \stackrel{6}{\longleftrightarrow} \mathrm{H}_{2}+2 \underline{O}
\end{gathered}
$$

The underlined atoms denote atoms belonging to the metal oxide lattice.

\subsection{Automatic Network Generation}

The species and elementary steps involved in the reaction mechanism discussed in the previous section are generated

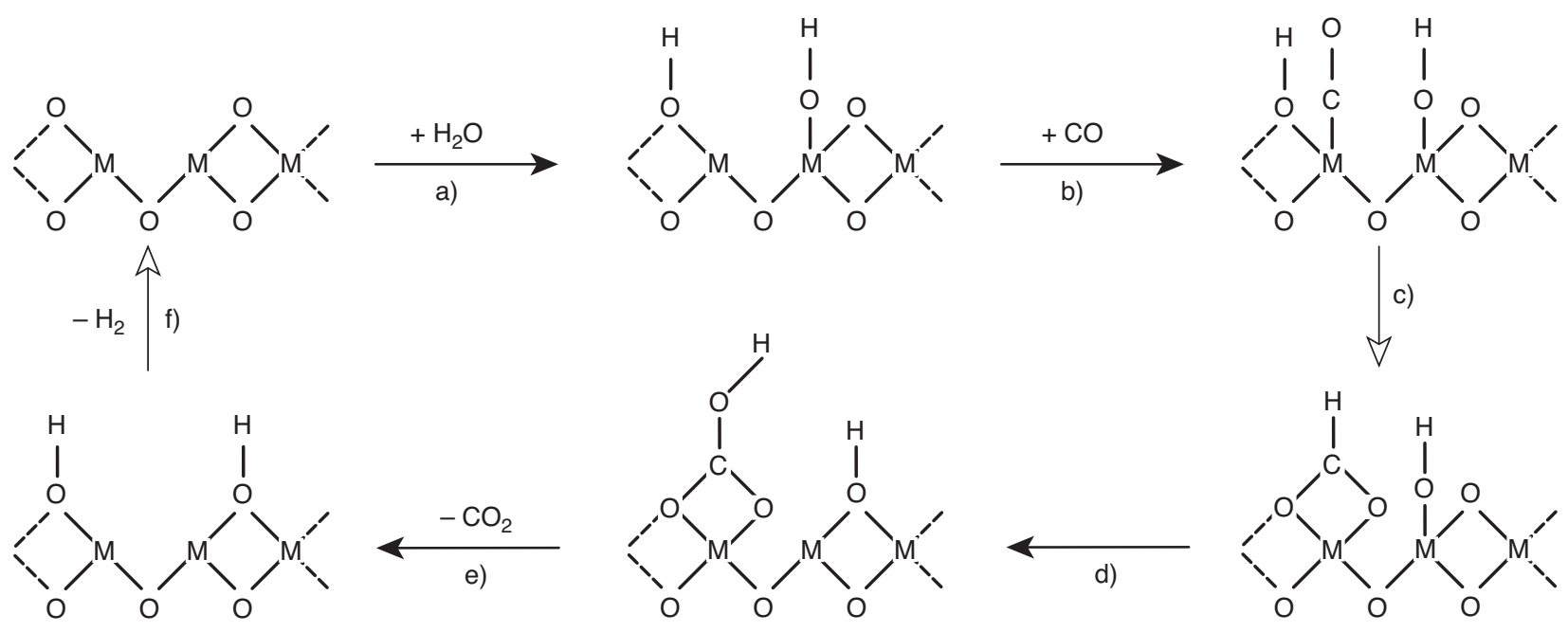

Figure 1

Water-gas shift reaction pathway according to the formate mechanism: a) dissociative chemisorption of water on an anion vacancy and a surface oxygen, b) associative chemisorption of carbon monoxide on an anion vacancy, c) reaction of carbon monoxide with a hydroxyl group to form a formate species, d) reaction of the formate species to form bicarbonate species, e) desorption of carbon dioxide, f) desorption of hydrogen [42]. 
using a computer algorithm. Computer algorithms for reaction network generation were introduced by Clymans and Froment [45] for the thermal cracking of normal and branched alkanes. Later on, other network generation programs dealing with acid catalyzed and radical reactions have been developed [46-50]. Following a similar code structure, a network generation program for Fischer-Tropsch synthesis has been constructed. Although Fischer-Tropsch synthesis produces mostly linear alkanes and 1-alkenes, depending on the operating conditions, other products such as primary alcohols, methyl branched alkanes and internal alkenes can also be formed in significant amounts [11]. The network generation program is able to construct reaction networks containing such species. An upper carbon number is set by the user.

Molecules and elementary steps are represented in the program by means of Boolean matrices and standardized labels [9, 46-50]. In the Boolean matrices, the elements represent the existence of a bond between the non-hydrogen atoms in a particular molecule. If a bond exists, the corresponding matrix element is equal to one. Otherwise, the matrix element is equal to zero. Carbon, oxygen and metal atoms are distinguished by an adjacent column matrix added to the left border of the matrix [9]. The adjacent column was introduced by Vynckier and Froment for components that contain heteroatoms [47]. These binary relation matrices are useful for the algorithmic implementation of the chemical transformation in a reaction family, where, e.g., the bond forming/breaking involves the same reactive moiety and, hence, an easy operation rule can be implemented in the code. Additionally, by simple mathematical operations, $\beta$ - and higher connectivities between the atoms, which can be necessary to identify the reactive moieties, can be calculated [45].

The disadvantage of Boolean relation matrices is that they are expensive in terms of computer memory and are rather difficult to read for the end user. Standardized labels offer a more compact alternative to store the generated molecules and are easier to read. The standardized labels are vectors that represent the molecule unequivocally. Each atom in the molecule is characterized by a pair of numbers giving information on its degree of substitution and intrinsic character, related to the degree of priority of the atoms in the molecule. In order to preserve the uniqueness of the Boolean and vector representation, the atoms are numbered following a strict set of priority rules, based on IUPAC specifications. The numerical representation of species and elementary steps in Fischer-Tropsch synthesis has been explained in detail elsewhere [9].

A pseudo code explaining the sequential steps taken by the reaction network generation program is displayed in Figure 2. The generation and reaction of every intermediate species is guaranteed by a counter-based "while" loop.

The starting or "feed" molecule is the metal carbide species formed by carbon monoxide dissociation on the catalyst

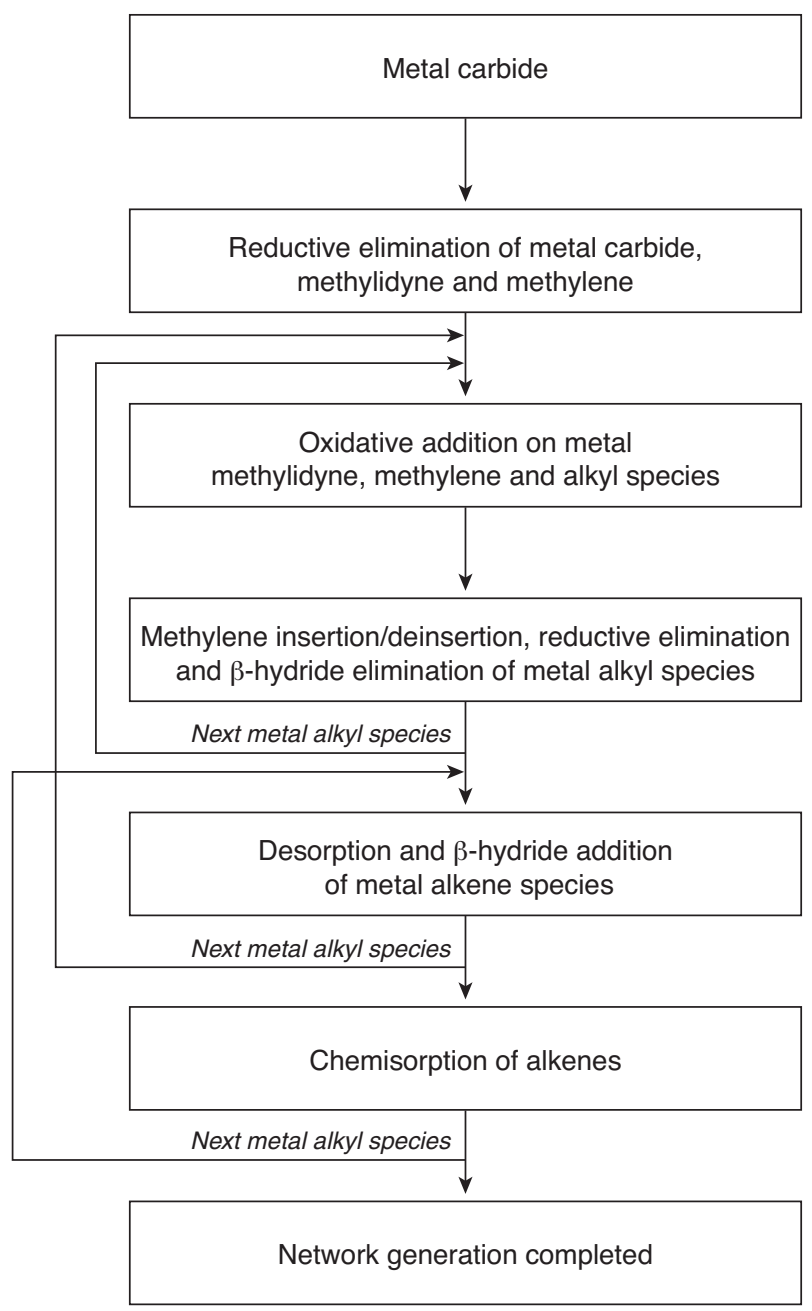

Figure 2

Pseudo code for the reaction network generation program for alkanes and alkenes starting from metal carbide.

surface. A rank number as revealed during the execution run identifies the generated molecules. The specific rank numbers are stored in the corresponding reaction files and the molecules are stored in their particular files using the standardized labels. The program treats the stored molecules in a sequential way. The network generation is completed when all the molecules have undergone all the possible elementary reactions.

\section{SINGLE-EVENT MICROKINETICS}

The single-event methodology drastically reduces the number of adjustable kinetic parameters while preserving the fundamental character of a microkinetic model by using the reaction family concept. Usually, a series of elementary steps can 
be grouped into a particular reaction family if the chemical transformation occurs on analogous reactive moieties of homologous series of compounds.

\subsection{The Single-Event Concept}

Based on the transition state theory, the kinetic coefficient can be divided in a symmetry dependent factor, i.e., the ratio between global symmetry numbers of reactant(s) and transition state, and the so-called single-event kinetic coefficient $\tilde{k}$, constant for a particular type of elementary step, as follows:

$$
\begin{gathered}
k=\frac{\sigma_{g l, r}}{\sigma_{g l, \neq}} \frac{k_{B} T}{h} \exp \left(\frac{\Delta \tilde{S}^{0, \neq}}{R}\right) \exp \left(\frac{\Delta H^{0, \neq}}{R T}\right) \\
k=\frac{\sigma_{g l, r}}{\sigma_{g l, \neq}} \tilde{k}
\end{gathered}
$$

Global symmetry numbers of reactants $\sigma_{g l, r}$ and transition state $\sigma_{g l, \neq}$ depend on the number and position of methyl branches, which stipulate the occurrence of chiral carbon atoms and symmetry and are calculated during reaction network generation.

Since the single-event kinetic coefficient for a given type of elementary step $\tilde{k}$ is assumed constant, the number of adjustable parameters in a SEMK model is equal to the number of reaction families. Based on constraints imposed by thermodynamic consistency, however, the number of adjustable parameters can be further reduced.

\subsection{Thermodynamic Consistency}

Thermodynamic consistency in a complex reaction network is not straightforward due to the lack of thermochemical data for surface species. Violating thermodynamic consistency leads to errors in conversion and selectivities as well as to a distortion of the equilibrium coefficients [51]. In this work, the thermodynamic consistency of the individual elementary reactions and the overall Fischer-Tropsch reaction is guaranteed by using the principle of microscopic reversibility. The number of adjustable kinetic parameters can be further reduced by calculating the equilibrium constants of every elementary reaction. At the level of an elementary step, thermodynamic consistency can be easily satisfied, and in fact, this consistency is used to calculate the single-event pre-exponential factor and the activation energy of the reverse elementary steps.

Activation enthalpies and single-event pre-exponential factors for a reverse elementary step $i$, are calculated as:

$$
\begin{gathered}
E_{a, i}^{r e v}=E_{a, i}^{f o r}-\Delta H_{R, i}^{0} \\
\tilde{A}_{i}^{r e v}=\tilde{A}_{i}^{f o r} \exp \left(-\frac{\Delta \tilde{S}_{R, i}^{0}}{R}\right)
\end{gathered}
$$

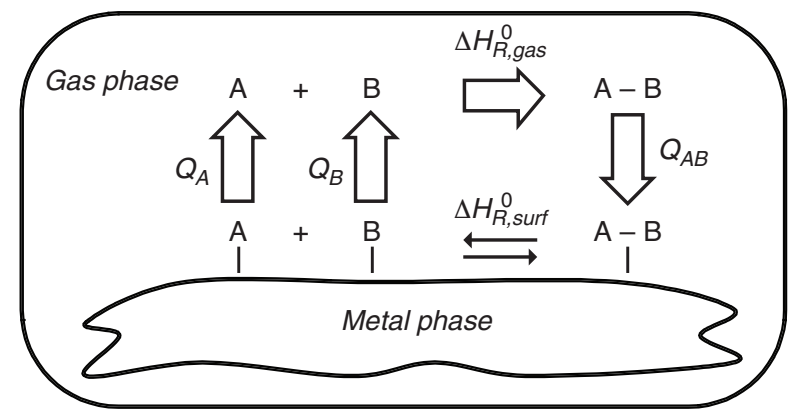

Figure 3

Born-Haber thermodynamic cycle for a surface reaction. In this figure, the calculation of the standard surface reaction enthalpy is illustrated. A completely analogous cycle can be drawn for the calculation of the surface reaction entropy.

Enthalpies and entropies are state functions and, hence, enthalpies and entropies for surface reactions are linear combinations of the enthalpies and entropies of the analogous gas-phase reactions in agreement to the Born-Haber cycle, as displayed in Figure 3.

Hence, the standard enthalpy of a surface reaction is defined as:

$$
\Delta H_{R, \text { surf }}^{0}=\Delta H_{R, \text { gas-phase }}^{0}+\sum_{j=1}^{\text {react }} v_{j} Q_{j}-\sum_{k=1}^{\text {prod }} v_{k} Q_{k}
$$

where $Q$ is the chemisorption enthalpy, positive by convention.

The same type of equation holds for the calculation of standard entropies of surface reactions.

Enthalpies and entropies of gas-phase molecules are calculated with a group additivity method applied to alkanes, alkenes and radicals [52-54], or from tabulated values $[55,56]$. Chemisorption enthalpies are calculated by a phenomenological method as a function of gas-phase bond energies and atomic chemisorption enthalpies of the atoms in contact with the surface [8]. Atomic chemisorption enthalpies depend on the particular metal surface and hence, are adjustable parameters in the model.

Equations derived from statistical thermodynamics are used to calculate chemisorption entropies for the surface and transition state species assuming the loss of certain degrees of freedom from the associated gas-phase molecule. The calculation of the single-event pre-exponential factors for the forward and reverse steps is given in detail elsewhere [57].

\subsection{Kinetic Equations}

Rate equations are function of the partial pressures of the participating gas-phase molecules and the concentration of the surface species. For a reaction step involving two actives sites, the probability of finding adjacent occupied or unoccupied atoms is included in the rate expressions [58]. 
The net formation rate of an alkane $l$ and an alkene $k$, respectively, are given by:

$$
\begin{aligned}
& R_{\text {alkane }, l}=\sum_{i=1}^{n m a l k y l s} \frac{1}{2} z \frac{\sigma_{g l, r}}{\sigma_{g l, \neq}} \tilde{k}_{r e, M-\text { alkyls }} C_{M-\text { alkyl }, i \rightarrow l} \frac{C_{M-H}}{C_{M_{\text {tot }}}} \\
& -\frac{1}{2} z \frac{\sigma_{g l, r}}{\sigma_{g l, \neq}} \tilde{k}_{\text {oa, alkanes }} p_{\text {alkane }, l} C_{M} \frac{C_{M}}{C_{M_{\text {tot }}}} \\
& R_{\text {alkene }, k}=\frac{\sigma_{g l, r}}{\sigma_{g l, \neq}} \tilde{k}_{\text {des }, M \text {-alkenes }} C_{M-\text { alkene }, j \rightarrow k} \\
& -\frac{\sigma_{g l, r}}{\sigma_{g l, \neq}} \tilde{k}_{\text {chem }} p_{\text {alkene }, k} C_{M}
\end{aligned}
$$

For the water-gas shift reaction, also a microkinetic model is applied. Consequently, similar net production rates are written for carbon dioxide and water [57].

\section{REGRESSION RESULTS AND DISCUSSION}

The total number of adjustable parameters is 14 , i.e., 10 activation energies and 4 atomic chemisorption enthalpies. An overview of the elementary steps and reaction families considered as well as the corresponding adjustable parameters is given in Table 3 . The activation energies for the dissociation of carbon monoxide, step (3), reductive elimination of metal carbide, step (4), metal methylidyne, step (5), metal methylene, step (6), metal oxide, step (12) and metal hydroxyl, step

TABLE 3

Estimated forward activation energies and atomic chemisorption enthalpies with the $95 \%$ confidence interval, and reverse activation energies for an iron-based catalyst obtained by regression of experimental data at $T=623 \mathrm{~K}, p_{\text {tot }}=0.6-2.1 \mathrm{MPa}$,

$\mathrm{H}_{2} / \mathrm{CO}=2-6 \mathrm{~mol} / \mathrm{mol}$ and $W / F_{\mathrm{CO}}^{0}=9.2-63.0 \mathrm{~kg} \mathrm{~s} / \mathrm{mol}$

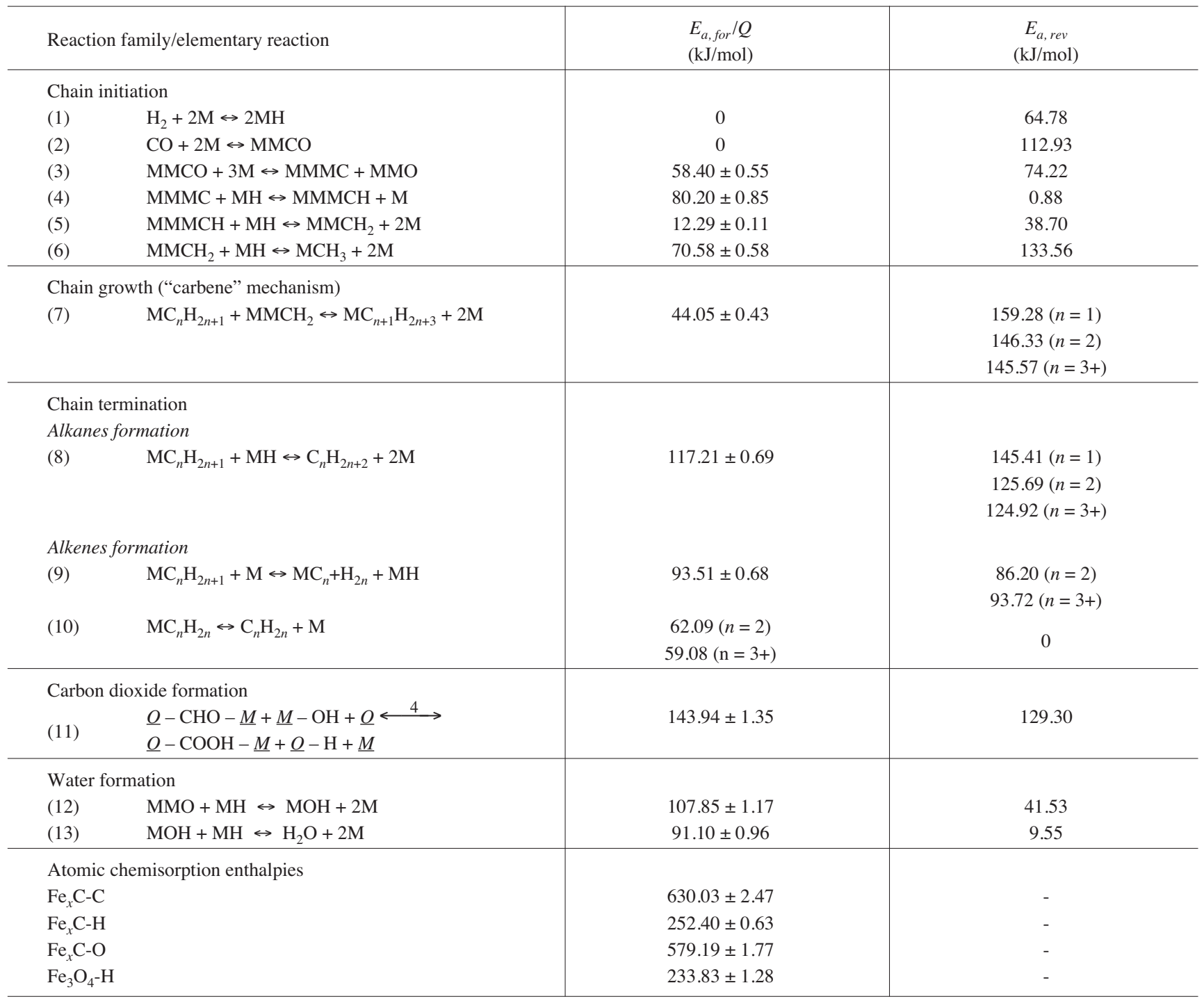



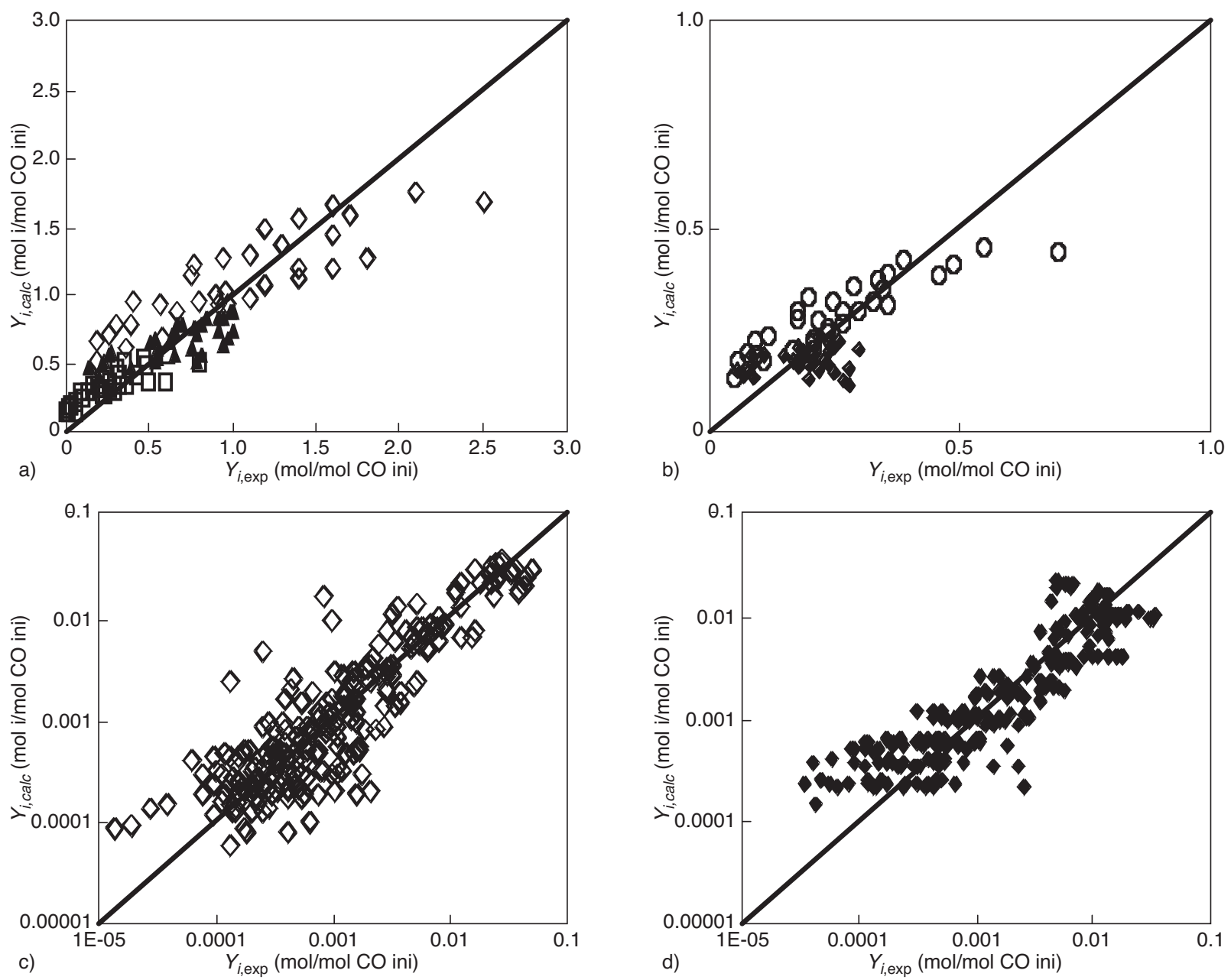

Figure 4

Experimental and calculated molar yields of a) carbon monoxide $(\boldsymbol{\Lambda})$, hydrogen $(\boldsymbol{\diamond})$ and water $(\mathbf{\square})$, b) carbon dioxide $(\boldsymbol{\bullet})$ and methane $(\mathbf{0})$, c) $n$-alkanes containing up to ten carbon atoms, and d) 1-alkenes containing up to ten carbon atoms, over an iron-based catalyst at $T=623 \mathrm{~K}$, $p_{\text {tot }}=0.6-2.1 \mathrm{MPa}, \mathrm{H}_{2} / \mathrm{CO}=2-6 \mathrm{~mol} / \mathrm{mol}$ and $W / F_{\mathrm{CO}}^{0}=9.2-63.0 \mathrm{~kg} \mathrm{~s} / \mathrm{mol}$. Molar yields are calculated with the set of parameters given in Table 3 by integration of Equation (5).

(13), methylene insertion, step (7), reductive elimination towards alkanes, step (8) and $\beta$-hydride elimination, step (9), are adjusted by model regression to experimental data. Also, the chemisorption enthalpies of carbon, hydrogen and oxygen are used as adjustable parameters. The water-gas shift can be described by the activation energy of the kinetically relevant elementary step, step (11), and by the atomic chemisorption of hydrogen on magnetite. The total number of degrees of freedom amounts to 676 .

The parameter estimates together with their $95 \%$ individual confidence intervals are given in Table 3 . Activation energies for the reverse elementary steps, calculated with the reaction enthalpy at $623 \mathrm{~K}$ with Equation (19), are also included in this table. Individual reaction enthalpies for the different carbon numbers are used and, hence, different reverse activation energies are obtained. The parity diagrams for the light mole- cules, $n$-alkanes and 1-alkenes are given in Figure 4. The parity diagrams show that the major experimentally observed trends are captured by the model, while some overestimation occurs at lower values and underestimation at higher values, as also evident from Figure 5. The spread at the lower values in the parity diagrams for the alkanes and alkenes, Figures $4 \mathrm{c}$ and $\mathrm{d}$, is partly due to the logarithmic scale used. In general, the fit, however, is good for all reactants and products. Further, the agreement between experimentally obtained and model calculated concentration profiles of the non-hydrocarbon molecules plus methane and product distributions of $n$-alkanes and 1-alkenes is given in Figure 5 and Figure 6, for two different experimental conditions. The deviation observed in the ASF distribution for methane and ethylene, i.e., higher methane molar yield and lower ethylene molar yield than the theoretical ASF plot, is adequately described 

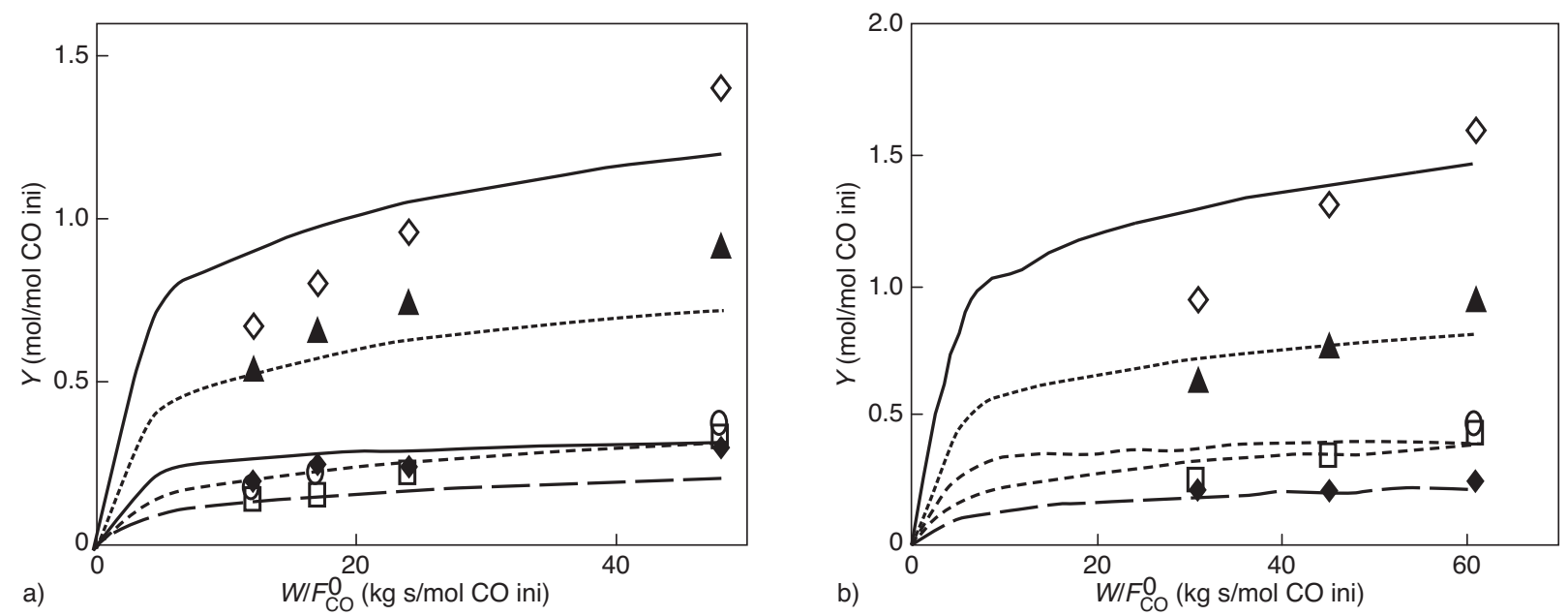

Figure 5

Calculated and experimental molar yields of carbon monoxide $(\boldsymbol{\Lambda})$, hydrogen $(\diamond)$, carbon dioxide $(\diamond)$, water $(\mathbf{\square})$ and methane $(\mathbf{0})$ with respect to the space-time at a) $T=623 \mathrm{~K}, p_{\text {tot }}=1.6 \mathrm{MPa}, \mathrm{H}_{2} / \mathrm{CO}=3 \mathrm{~mol} / \mathrm{mol}$ and b) $T=623 \mathrm{~K}, p_{\text {tot }}=1.6 \mathrm{MPa}, \mathrm{H}_{2} / \mathrm{CO}=4 \mathrm{~mol} / \mathrm{mol}$. Full lines are calculated with the set of parameters given in Table 3 by integration of Equation (5).

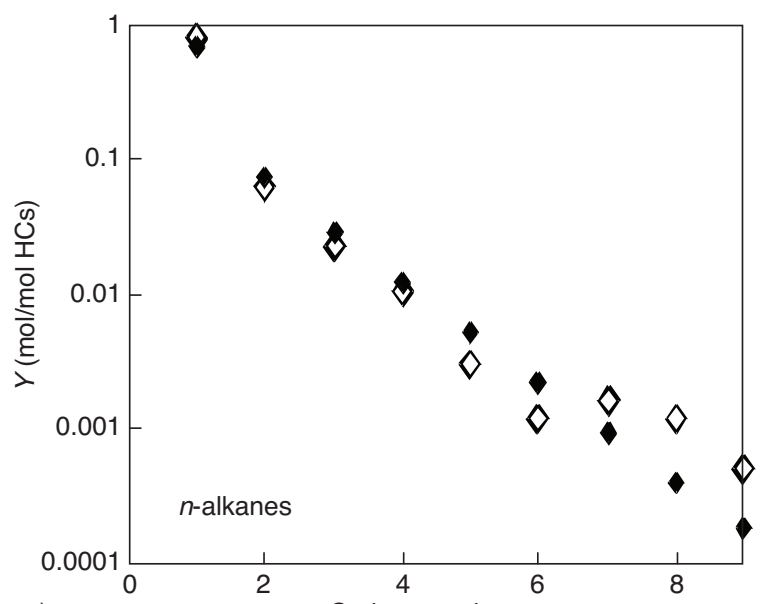

a)

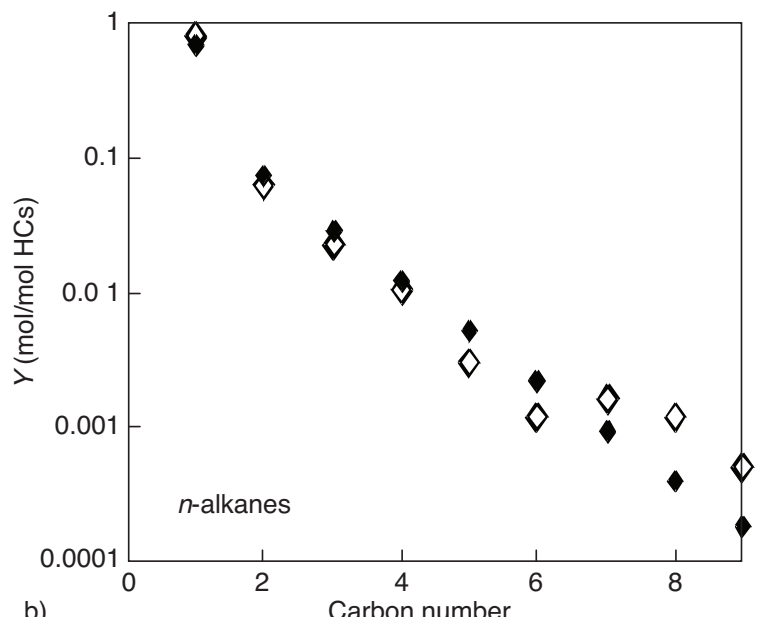

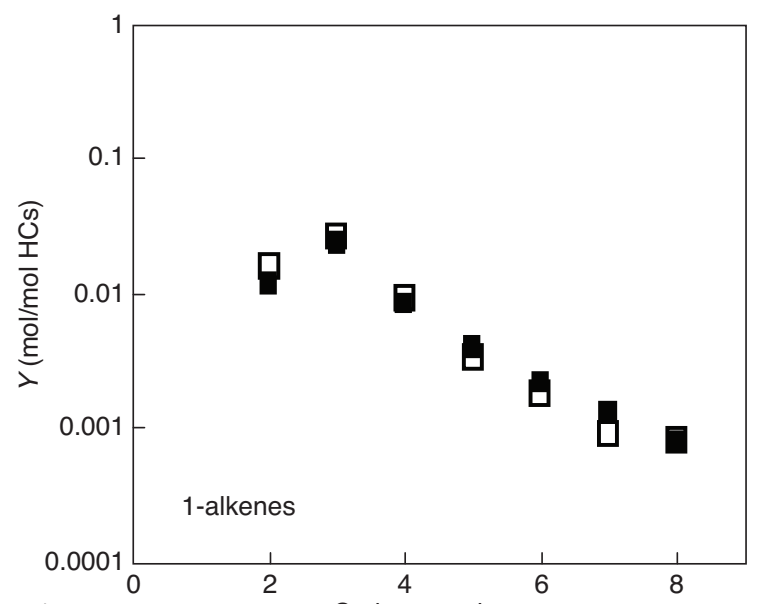

a)

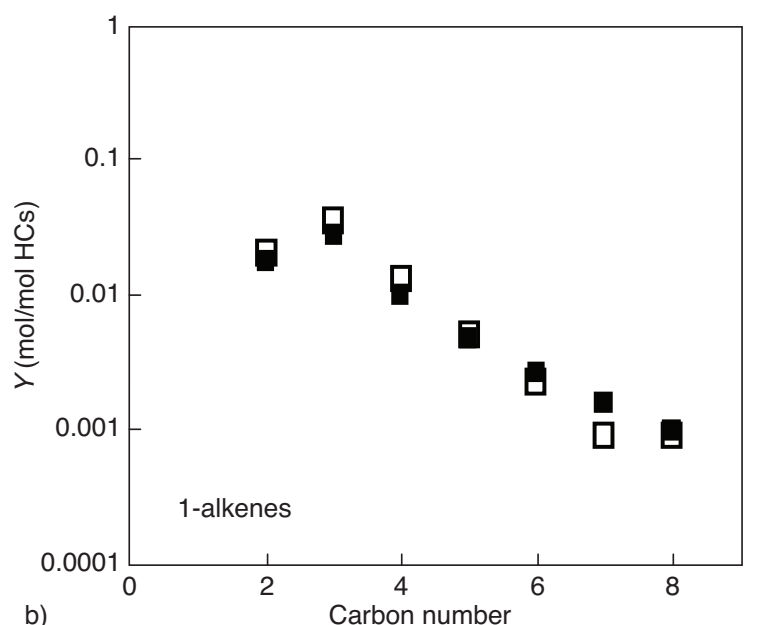

Figure 6

Experimental (open symbols) and calculated (closed symbols) product distributions for $n$-alkanes and 1-alkenes containing up to 9 carbon atoms at a) $T=623 \mathrm{~K}, p_{\text {tot }}=1.6 \mathrm{MPa}, \mathrm{H}_{2} / \mathrm{CO}=3 \mathrm{~mol} / \mathrm{mol}, W / F_{\mathrm{CO}}^{0}=48 \mathrm{~kg} \mathrm{~s} / \mathrm{mol}$ and b) $T=623 \mathrm{~K}, p_{\text {tot }}=1.6 \mathrm{MPa}, \mathrm{H}_{2} / \mathrm{CO}=4 \mathrm{~mol} / \mathrm{mol}, W / F_{\mathrm{CO}}^{0}=61 \mathrm{~kg}$ $\mathrm{s} / \mathrm{mol}$. Closed symbols are calculated with the set of parameters given in Table 3 by integration of Equation (5) with the corresponding net production rates (22) and (23). 
with a carbon number independent activation energy for the formation of $n$-alkanes and 1-alkenes, as a consequence of the different global symmetry numbers found for the $\mathrm{C}_{1}$ and $\mathrm{C}_{2}$ species.

The $F$ value for the significance of the global regression is 150 , fairly exceeding the tabulated value of 2.79 . The parameter significance was verified by applying the $t$ test for a 95\% probability level. All the $t$ values were higher than the critical value of 1.963 . The higher $t$ values are obtained for the atomic chemisorption enthalpies and for the activation energies of the reductive elimination towards alkanes, step (8) in Table 3, and the $\beta$-hydride elimination, step (9), which are the more important parameters determining the product distribution. The smallest $t$ value was 181, obtained for the reductive elimination of metal oxide species, step (12) in Table 3. Correlation coefficients between the individual parameter estimates were much lower than the absolute value of 0.95 obtained for the carbon and oxygen chemisorption enthalpies, implying a non-conclusive correlation between parameters.

The estimated parameter values are within ranges of reasonable values, and comparable to values calculated by other kinetic models applied to iron-based catalysts [27, 59, $60]$. The above results and discussion illustrates the adequacy of the model. Further improvements could be pursued, e.g., by adjusting the distribution between the oxide and the carbide phase or by implementing additional and or alternative reaction pathways, however, in view of overparameterization, this has not been performed.

\section{CONCLUSIONS}

In addition to acid catalyzed and thermal reactions, the singleevent methodology can also be applied to metal catalyzed reactions. 14 adjustable parameters suffice for a mechanistic description of Fischer-Tropsch synthesis, including the water-gas shift reaction, i.e., 10 activation energies and 4 atomic chemisorption enthalpies. Pre-exponential factors can be obtained from first principles with sufficient accuracy. Apart from the initiation steps, three reaction families are required for an adequate simulation of experimental data, i.e., methylene insertion, reductive elimination and $\beta$-hydride elimination. The corresponding reaction network was automatically generated using Boolean relation matrices and vector labels.

The generated reaction network based on the "carbene" mechanism for hydrocarbon formation and the formate mechanism for water-gas shift allows to describe the FischerTropsch product slate on an iron catalyst with physically meaningful parameters. In particular, the deviations from the typical ASF product distribution observed at low carbon numbers is quantitatively captured with carbon number independent adjustable parameters. Deviations from the ASF distribution at higher conversions are the subject of future work.

\section{ACKNOWLEDGEMENTS}

G. L. B. thanks the Institut français du pétrole for financial support. This work was partly carried out in the framework of the Interuniversity Attraction Poles Programme funded by the Belgian Science Policy.

\section{REFERENCES}

1 Froment G.F. (1991) Kinetic Modeling of Complex Catalytic Reactions, Revue de l'Institut français du pétrole 46, 4, 491-500.

2 Verstraete J. (1997) Kinetische studie van de katalytische reforming van nafta over een $\mathrm{Pt}-\mathrm{Sn} / \mathrm{Al}_{2} \mathrm{O}_{3}$ katalysator, $P h D$ Thesis, Ghent University, Ghent.

3 Schweitzer J.M., Galtier P., Schweich D. (1999) A single events kinetic model for the hydrocracking of paraffins in a three-phase reactor, Chem. Eng. Sci. 54, 13-14, 2441-2452.

4 Dewachtere N.V., Santaella F., Froment G.F. (1999) Application of a single-event kinetic model in the simulation of an industrial riser reactor for the catalytic cracking of vacuum gas oil, Chem. Eng. Sci. 54, 15-16, 3653-3660.

5 Van Engelandt W. (1998) Reformuleren van Nafta door Selectieve Hydrocracking, PhD Thesis, Ghent University, Ghent.

6 Klinke D.J., Broadbelt L.J. (1999) Construction of a mechanistic model of Fischer-Tropsch synthesis on $\mathrm{Ni}(111)$ and $\mathrm{Co}(0001)$ surfaces, Chem. Eng. Sci. 54, 15-16, 3379-3389.

7 Storsaeter S., Chen D., Holmen A. (2006) Microkinetic modelling of the formation of $\mathrm{C}_{1}$ and $\mathrm{C}_{2}$ products in the Fischer-Tropsch synthesis over cobalt catalysts, Surf. Sci. 600, 10, 2051-2063.

8 Shustorovich E., Sellers H. (1998) The UBI-QEP method: a practical theoretical approach to understanding chemistry on transition metal surfaces, Surf. Sci.Rep. 31, 1-3, 5-119.

9 Lozano-Blanco G., Thybaut J.W., Galtier P., Surla K., Marin G.B. (2006) Fischer-Tropsch synthesis: development of a microkinetic model for metal catalysis, Oil Gas Sci. Technol. - Rev. IFP 61, 4, 489-496.

10 Temkin O.N., Zeigarnik A.V., Kuz'min A.E., Bruk L.G., Slivinskii E.V. (2002) Construction of the reaction networks for heterogeneous catalytic reactions: Fischer-Tropsch synthesis and related reactions, Russ. Chem. $B+\mathbf{5 1}, 1,1-36$.

11 Dry M.E. (2004) Present and future applications of the FischerTropsch process, Appl. Catal. A-Gen. 276, 1-2, 1-3.

12 Dry M.E., Steynberg A.P. (2004) Commercial Fischer-Tropsch process applications, Stud. Surf. Sci. Catal.: Fischer-Tropsch Technology 152, 406-481.

13 Dry M.E. (2002) The Fischer-Tropsch process: 1950-2000, Catal. Today 71, 3-4, 227-241.

14 Dry M.E. (1990) The Fischer-Tropsch process - commercial aspects, Catal. Today 6, 13-206.

15 Hindermann J.P., Hutchings G.J., Kiennemann A. (1993) Mechanistic aspects of the formation of hydrocarbons and alcohols from CO hydrogenation, Catal. Rev. 35, 1, 1-127.

16 Anderson R.B. (1984) The Fischer-Tropsch synthesis, Academic Press, New York.

17 Iglesia E., Reyes S.C., Madon R.J., Soled S.L. (1993) Selectivity control and catalyst design in the Fischer-Tropsch synthesis sites, pellets, and reactors, Adv. Catal. 39, 39, 221-302.

18 Yakubovich M.N. (2002) Equations for the molecular mass distribution of hydrocarbons formed in $\mathrm{CO}$ hydrogenation on a cobalt-zirconium catalyst, Kinet. Catal.+ 43, 1, 67-72.

19 Patzlaff J., Liu Y., Graffmann C., Gaube J. (1999) Studies on product distributions of iron and cobalt catalyzed FischerTropsch synthesis, Appl. Catal. A-Gen. 186, 1-2, 109-119.

20 Iglesia E., Reyes S.C., Madon R.J. (1991) Transport-enhanced alpha-olefin readsorption pathways in Ru-catalyzed hydrocarbon synthesis, J. Catal. 129, 1, 238-256. 
21 Kuipers E.W., Vinkenburg I.H., Oosterbeek H. (1995) Chainlength dependence of alpha-olefin readsorption in FischerTropsch synthesis, J. Catal. 152, 1, 137-146.

22 Lox E.S. (1987) De synthese van koolwaterstoffen uit koolstofmonoxyde en waterstof, PhD Thesis, Ghent University, Ghent.

23 Lox E., Coenen F., Vermeulen R., Froment G.F. (1988) A versatile bench-scale unit for kinetic-studies of catalytic reactions, Ind. Eng. Chem. Res. 27, 4, 576-580.

24 Lox E.S., Froment G.F. (1993) Kinetics of the Fischer-Tropsch reaction on a precipitated promoted iron catalyst. 1. Experimental procedure and results, Ind. Eng. Chem. Res. 32, 1, 61-70.

25 Lox E.S., Marin G.B., Degrave E., Bussiere P. (1988) Characterization of a promoted precipitated iron catalyst for Fischer-Tropsch synthesis, Appl. Catal. 40, 1-2, 197-218.

26 Froment G.F., Bischoff K.B. (1990) Chemical reactor analysis and design, 2nd ed., Wiley, New York, p. xxxiv, 664 p.

27 Lox E.S., Froment G.F. (1993) Kinetics of the Fischer-Tropsch reaction on a precipitated promoted iron catalyst. 2 . Kinetic modeling, Ind. Eng. Chem. Res. 32, 1, 71-82.

28 Froment G.F. (1975) Model discrimination and parameter estimation in heterogeneous catalysis, Aiche J. 21, 6, 1041-1057.

29 Froment G.F., Hosten L.H. (1981) Catalytic kinetics: modelling, Catalysis: science and technology, Anderson J.R., Boudart M. (eds), Springer, Berlin, Vol. 2, pp. 97-170.

30 Marquardt D.W. (1963) An algorithm for least-squares estimation of non-linear parameters, J. Soc. Ind. Appl. Math. 11, 2, 431-441.

31 Rosenbrock H.H. (1960) An automatic method for finding the greatest or least value of a function, Comput. J.3, 175-184.

32 Boggs P.T., Tolle J.W. (1989) A strategy for global convergence in a sequential quadratic-programming algorithm, SIAM J. Numer. Anal. 26, 3, 600-623.

33 http://netlib.org.

34 Claeys P., Van Steen E. (2004) Basic studies, Fischer-Tropsch Technology, Catalysis, S. i. S. S. a., Ed. Elsevier, Amsterdam, Vol. 152.

35 Overett M.J., Hill R.O., Moss J.R. (2000) Organometallic chemistry and surface science: mechanistic models for the FischerTropsch synthesis, Coordin. Chem. Rev. 206, 581-605.

36 Bent B.E. (1996) Mimicking aspects of heterogeneous catalysis: generating, isolating, and reacting proposed surface intermediates on single crystals in vacuum, Chem. Rev. 96, 4, 1361-1390.

37 Toyir J., Leconte M., Niccolai G.P., Basset J.M. (1995) Hydrogenolysis and homologation of 3,3-dimethyl-1-butene on $\mathrm{Ru} / \mathrm{SiO}_{2}$ catalyst - implications for the mechanism of carbon-carbon bond formation and cleavage on metal-surfaces, J. Catal. 152, 2, 306-312.

38 Zaera F. (2002) Selectivity in hydrocarbon catalytic reforming: a surface chemistry perspective, Appl. Catal. A-Gen. 229, 1-2, 75-91.

39 Newsome D.S. (1980) The water-gas shift reaction, Catal. Rev. 21, 2, 275-318.

40 Rao K.R.P.M., Huggins F.E., Mahajan V., Huffman G.P., Rao V.U.S. (1994) The role of magnetite in Fischer-Tropsch synthesis, Hyperfine Interact. 93, 1-4, 1745-1749.

41 Zhang H.B., Schrader G.L. (1985) Characterization of a fused iron catalyst for Fischer-Tropsch synthesis by in situ laser raman-spectroscopy, J. Catal. 95, 1, 325-332.

42 Rethwisch D.G., Dumesic J.A. (1986) The effect of metal-oxygen bond strength on properties of oxides. 2. Water-gas shift over bulk oxides, Appl. Catal. 21, 1,97-109.
43 van Santen R.A., Niemantsverdriet J.W. (1995) Chemical kinetics and catalysis, Plenum Press, New York, p. xi, 280.

44 Teng B.T., Chang J., Yang J., Wang G., Zhang C.H., Xu Y.Y., Xiang H.W., Li Y.W. (2005) Water gas shift reaction kinetics in Fischer-Tropsch synthesis over an industrial Fe-Mn catalyst, Fuel 84, 7-8, 917-926.

45 Clymans P.J., Froment G.F. (1984) Computer-generation of reaction paths and rate-equations in the thermal-cracking of normal and branched paraffins, Comput. Chem. Eng. 8, 2, 137-142.

46 Svoboda G.D., Vynckier E., Debrabandere B., Froment G.F. (1995) Single-event rate parameters for paraffin hydrocracking oil a Pt/US-Y zeolite, Ind.Eng. Chem. Res. 34, 11, 3793-3800.

47 Vynckier E., Froment G.F. (1991) Modeling of the kinetics of complex processes based upon elementary steps, Kinetic and Thermodynamic Lumping of Multicomponent Mixtures, Astarita G., Sandler S.I. (eds), Elsevier, Amsterdam.

48 Feng W., Vynckier E., Froment G.F. (1993) Single-event kinetics of catalytic cracking, Ind. Eng. Chem. Res. 32, 12, 2997-3005.

49 Wauters S., Marin G.B. (2001) Computer generation of a network of elementary steps for coke formation during the thermal cracking of hydrocarbons, Chem. Eng. J. 82, 1-3, 267-279.

50 Baltanas M.A., Froment G.F. (1985) Computer-generation of reaction networks and calculation of product distributions in the hydroisomerization and hydrocracking of paraffins on Pt-containing bifunctional catalysts, Comput. Chem. Eng. 9, 1, 71-81.

51 Mhadeshwar A.B., Wang H., Vlachos D.G. (2003) Thermodynamic consistency in microkinetic development of surface reaction mechanisms, J. Phys. Chem. B 107, 46, 12721-12733.

52 Cohen N. (1992) Thermochemistry of alkyl free-radicals, $J$. Phys. Chem. 96, 22, 9052-9058.

53 Cohen N. (1996) Revised group additivity values for enthalpies of formation (at $298 \mathrm{~K}$ ) of carbon-hydrogen and carbon-hydrogenoxygen compounds, J. Phys. Chem. Ref. Data 25, 6, 1411-1481.

54 Cohen N., Benson S.W. (1993) Estimation of heats of formation of organic-compounds by additivity methods, Chem. Rev. 93, 7 , 2419-2438.

55 http://webbook.nist.gov/chemistry.

56 Lide D.R. (2003) CRC handbook of chemistry and physics: a ready-reference book of chemical and physical data, 84th ed., David R. Lide (ed.), CRC, Boca Raton, Fla., London, p. 1 v (various pagings).

57 Lozano-Blanco G., Thybaut J.W., Surla K., Galtier P., Marin G.B. (in preparation).

58 Boudart M., Djéga-Mariadassou G. (1984) Kinetics of heterogeneous catalytic reactions, Princeton University Press, Princeton, N.J., p. xviii, 222 p.

59 Teng B.T., Chang J., Zhang C.H., Cao D.B., Yang J., Liu Y., Guo X.H., Xiang H.W., Li Y.W. (2006) A comprehensive kinetics model of Fischer-Tropsch synthesis over an industrial Fe-Mn catalyst, Appl. Catal. A-Gen. 301, 1, 39-50.

60 Yang J., Liu Y., Chang J., Wang Y.N., Bai L., Xu Y.Y., Xiang H.W., Li Y.W., Zhong B. (2003) Detailed kinetics of FischerTropsch synthesis on an industrial Fe-Mn catalyst, Ind. Eng. Chem. Res. 42, 21, 5066-5090.

Final manuscript received in April 2009 Published online in October 2010 